\title{
Varied Aerobic Intensity Effects on Hormonal, Anthropometric, and Health Changes
}

\author{
Elizabeth C. Wuorinen*, Kylie Cowens, Stefan Wuorinen, Sophie LeClerc, Jeffrey Wuorinen \\ Department of Biology and Physical Education, College of Science and Mathematics, Norwich University, \\ Northfield, Vermont, USA \\ Email: $\underline{\text { ewuorine@norwich.edu }}$
}

Received 24 June 2014; revised 23 July 2014; accepted 22 August 2014

Copyright $@ 2014$ by authors and Scientific Research Publishing Inc.

This work is licensed under the Creative Commons Attribution International License (CC BY). http://creativecommons.org/licenses/by/4.0/

cC) (7) Open Access

\section{Abstract}

The purpose of this project was to examine the effects of a 20-week training study, which included varied aerobic exercise intensity and identical resistance and flexibility training, on circumference, body mass, hormonal, health/fitness and psychophysical measures. Methods: Thirty-two of 40 recruited overweight middle-aged women were randomized into two training groups: low-intensity (LOW: $-40 \% \mathrm{VO}_{2 \text { peak }}$ ) and high-intensity ( $\mathrm{HIGH}:-80 \% \mathrm{VO}_{2 \text { peak }}$ ), for a 20 -week training program. Participants were weighed, measured, underwent $\mathrm{Vo}_{2 \text { peak }}$ graded exercise tests, and had blood drawn pre-training and at 10- and 20-weeks. Results: Both groups experienced significant body mass loss at 10- and 20-weeks (LOW: $p<0.05 ; p<0.01$ and HIGH: $p<0.001$ and $p<0.01$ respectively) and circumference loss $(10$-weeks-LOW: waist, hip, and thigh regions $(p<0.001)$; HIGH: arm ( $<<0.05)$, waist $(p<0.05)$, hip $(p<0.01)$, thigh $(p<0.05) ; 20$-weeks-LOW: arm, waist, hip, thigh ( $<$ 0.001); HIGH: arm, hip, thigh $(p<0.001)$ and waist $(p<0.01))$. Ghrelin levels were elevated in the LOW group $(p<0.05)$ by the end of the 20 -weeks of training, whereas the HIGH group had a significant decrease $(p<0.01)$ at that time. Over the training period, leptin concentrations diminished significantly in both groups (LOW $p<0.01$; HIGH $p<0.05$ ) and were correlated to the body mass/anthropometric changes. Discussion: Both low- and high-intensity produced significant loss in body mass and circumference measurements suggesting that it is not the intensity of exercise, but rather overall energy expenditure that should be considered. The advantage of high-intensity aerobic exercise is that it requires less time to produce the desired energy expenditure. The changes in ghrelin and leptin may have contributed to the energy intake during laboratory trials.

\section{Keywords}

Middle-Aged Women, Aerobic Training, Resistance Training, Metabolites, Hormones, Circumference

\footnotetext{
*Corresponding author.
}

How to cite this paper: Wuorinen, E.C., et al. (2014) Varied Aerobic Intensity Effects on Hormonal, Anthropometric, and Health Changes. Open Journal of Molecular and Integrative Physiology, 4, 36-48. 


\section{Introduction}

The prevention of obesity and unhealthy weight gain will help to ward off many associated conditions such as cardiovascular disease, diabetes, arthritis, and other health disorders [1]-[3]. The desire to maintain or lose weight is a concern for many, yet the ability to do so is very challenging and incorporates behavioral components such as daily physical activity. Organizations concerned with the promotion of activity recommend that training programs integrate aerobic, resistance, and flexibility training as part of a total body regimen for health/ fitness benefits [4] [5], however many studies do not include all components. One objective of this study was to use a well-rounded training program and vary the aerobic intensity to determine whether the intensity difference had an effect on body mass and circumference measurements, hormones related to hunger/satiation signals, as well as other health/fitness related variables, over the course of a 20-week training program.

High-intensity exercise (HIGH) has been shown to suppress hunger and energy intake (EI) in acute laboratory studies [6] [7], however it is unknown how long that suppression will last. Stubbs et al. (2002) found dose-de pendent energy expenditure, with varied intensity aerobic exercise over the course of a week in lean young women, was accompanied by a partial compensation for the amount of energy being expended, yet the subjects remained in an energy deficit on exercise days. In a study conducted by Woo et al. (1982) [8], obese women underwent three conditions: sedentary, low- and moderate-intensity exercise; the women consumed the same EI in all three trials, but during exercise days, deficit occurred due to the added energy expenditure. Furthermore, they found that over 57-days, obese women did not compensate for exercise energy expenditure and lost weight [9]. HIGH programs have been shown to be effective in creating an overall body mass loss [10]-[12], yet the potential influence over hunger and subsequent caloric intake is variable under different situations.

It is well-known that hormones signal various energy states in the human body and are related to the conscious recognition of hunger and satiation. Of particular interest in this study were the hormones ghrelin and leptin, due to their well-documented correlation with hunger. Ghrelin, an orexigenic gut peptide, has been implicated in the mediation of hunger as there are sequential changes between increases in hunger and ghrelin concentrations during preprandial period and decreases in both upon EI [13]. In addition to the effects on shortterm hunger signaling, the increase in ghrelin concentrations following body weight loss were found to rise in parallel with hunger [14]. There is also evidence that HIGH acutely suppresses ghrelin [15] [16] and the associated changes with decreased hunger during and immediately following exercise have been postulated as a potential mechanism for exercise-induced hunger suppression [15]. Leptin, released in response to subcutaneous fat stores by adipose cells, relays information to the brain areas responsible for hunger, regarding the amount of energy availability [17]. There is a concomitant increase in hunger with a decrease in leptin concentrations and it is much easier to gain weight/fat back following losses; however when leptin is administered in the said state, hunger is suppressed [18]. Exercise-induced energy deficit lowers leptin concentrations [7] [19] [20] which in turn should stimulate hunger. The importance of these hormones in a 20-week training study was to see if there was any correlation between their secretion, hunger and anthropometric/body mass changes that might occur over time.

The purpose of this study was to create equal exercise energy expenditure utilizing varied intensity aerobic training, along with identical resistance, and flexibility training, to examine whether HIGH would be more effective in total body mass and circumference loss, as compared to a low intensity program (LOW). Furthermore, it was of interest to examine whether HIGH had greater health/fitness benefits over LOW, during the course of training, and whether hormonal changes were correlated with changes seen in physical structure. It was hypothesized that participants in HIGH would reduce body mass and circumference measurements more so than LOW under similar energy expenditures, over the 20 -weeks training, due to hunger suppression via the modulation of gut hormones, on exercise days.

\section{Methods}

\subsection{Experimental Approach to the Problem}

Eligible participants were randomized into one of two conditions: LOW $(n=16)$ or HIGH $(n=16)$. Participants were assessed pre-training, 10-week and after the 20-week intervention. Participants came to the Human Performance Laboratory one-week prior to starting the program for the following measurements: height, mass, circumference (arm, waist, hip, and thigh), resting heart rate and blood pressure, and cardiorespiratory assessment 
$\left(\mathrm{VO}_{2 \text { peak }}\right)$. Participants were asked to arrive at the laboratory, at $0700 \mathrm{~h}$, in a fasted state, having not consumed any caloric containing beverages or food since $2200 \mathrm{~h}$ the night before. To control for the effects of the menstrual cycle on outcome variables, premenopausal women had their visits between days 2 and 8 of their menstrual cycle. While in the laboratory, blood was drawn and participants completed visual analog scales (VAS) every 30 minutes, a $\mathrm{VO}_{\text {2peak }}$ graded exercise test (GXT) at 0730 , and were given an Ad libitum meal at $0830 \mathrm{~h}$. Subjects left after the final measurements were taken at $0900 \mathrm{~h}$.

\subsection{Subjects}

Thirty-two of 40 recruited, overweight (mean \pm SE; $87.88 \pm 2.05$ kilograms [kg]), middle-aged women (44.56 \pm $0.94)$ completed the present study. Inclusion criteria were 36 - 59 years of age, sedentary (structured exercise $<3$ days/week) overweight or mildly obese as assessed by body mass index (BMI: calculated as mass in kg/height [meters $\left.{ }^{2}\right] 25$ - 39), and not actively dieting. Exclusion criteria included having endocrine and metabolic disease other than hormonally-corrected hypothyroidism, musculo-skeletal disabilities that would preclude exercise, smoking, systolic blood pressure $>130 \mathrm{~mm} \mathrm{Hg}$ and a diastolic blood pressure of $>90 \mathrm{~mm} \mathrm{Hg}$, and not meeting other inclusion criteria listed. The Institutional Review Board, Human Subjects Committee of Norwich University, approved this study, and each participant provided written informed consent.

\subsection{Procedures}

\subsubsection{Body Mass and Circumference Measurements}

Body mass was measured in light clothing and without shoes to the nearest hundredth kilogram (kg) on a digital electronic scale (Tanita Ironman, Arlington Heights, IL). Circumference measurements were taken using a Gulick tape measure at the arm, minimal waist, hips, and thigh as described in the American College of Sports Medicine Guidelines.

\subsubsection{Cardiorespiratory Fitness Assessment.}

Participants completed a continuous $\mathrm{VO}_{\text {2peak }}$ treadmill protocol (GXT) one week prior to the start of the study, at 10-weeks and 20-weeks in order to determine whether their workload should increase in response to increased cardiorespiratory fitness. The GXT began at $0730 \mathrm{~h}$. Subjects began walking on a level treadmill at a speed of $53.6 \mathrm{~m} / \mathrm{min}$ with progressive increases in speed $(13.4 \mathrm{~m} / \mathrm{min})$ every 2 minutes until volitional fatigue. The protocol described was utilized as the training conditions would be on a level track, not on a varying treadmill, therefore assessing their peak values in relation to a flat surface would elicit the percentage of their peak $\mathrm{VO}_{2}$ they should be working at in order to burn approximately $400 \mathrm{kcals}$ during the aerobic portion of the program. Collection of ventilatory measurements were continuously sampled from a mixing-chamber and analyzed for gas flow and for oxygen $\left(\mathrm{O}_{2}\right)$ and carbon dioxide $\left(\mathrm{CO}_{2}\right)$ concentration by the MAX II exercise/metabolic testing cart (Naperville, IL). Heart rate was monitored with Polar heart rate monitors (Lake Success, NY). $\mathrm{VO}_{2 \text { peak }}$ was chosen as the highest $\mathrm{VO}_{2}(\mathrm{ml} / \mathrm{min})$ attained during the exercise protocol at each laboratory visit.

\subsubsection{Resting Blood Pressure and Heart Rate}

Resting blood pressure and heart rate were measured using the Omron automatic blood pressure monitor after arriving and acclimating to the laboratory setting for at least 15 minutes.

\subsubsection{Hunger Assessment during Laboratory Trials}

Hunger was assessed with a $100 \mathrm{~mm}$ visual analog scale (VAS) validated for variation in energy balance [21] where hunger was anchored with zero at one end and extreme valuation at the opposite end of the scale. The distances marked were converted to percentages of the full scale. Hunger was assessed every 30 minutes, beginning at $0700 \mathrm{~h}$, for the duration of each laboratory visit.

\subsubsection{Energy Intake during Laboratory Trials}

A meal was provided at $0830 \mathrm{~h}, 30$-minutes post exercise, in Ad libitum amounts to assess the pattern of EI as subjects progressed through the 20 -weeks of exercise. Subjects were given 30 minutes to consume as much as they desired. EI was assessed by food provided and any food left uneaten. The meal choices consisted of bagels, multigrain bread, peanut butter, jelly, cream cheese, apples, bananas, fruit yogurt, Honey Nut Cheerios ${ }^{\circledR}$, instant 
oatmeal, $1 \%$ milk, orange juice, coffee, tea, and water.

\subsubsection{Blood Collection and Hormone Measurements}

During each laboratory trial, blood samples were collected every 30 minutes between $0700 \mathrm{~h}$ and $0900 \mathrm{~h}$. Blood was kept chilled on ice in BD PST Vacutainer tubes with lithium heparin (Fisher Scientific, USA) to prevent clotting; plasma was separated by centrifugation and aliquoted into test tubes for later hormone determinations. Tubes were stored at $-70^{\circ} \mathrm{C}$ until analysis. Concentrations of total ghrelin and leptin were measured with radioimmunoassays (Linco Research, St. Louis, MO).

\subsubsection{Exercise Intervention}

Forty participants were randomized into two exercise groups: LOW or HIGH, and completed a 20-week supervised walking/running program. Participants were expected to exercise 5 days/week and only those who had at least $85 \%$ adherence to the program were considered for analysis, only 32 of the 40 subjects were considered for the final analysis due to inability to complete the program due to injury or illness and missing more than 15\% (or 15 days) of the total program. The remaining 32 subjects had $94 \%$ compliance to the program. The LOW group walked/jogged for 60 minutes at approximately $40 \%$ (range $37 \%$ - 43\%) of the $\mathrm{VO}_{2 \text { peak }}$ as assessed by heart rate monitors. The HIGH group walked/jogged for 30 minutes at approximately $80 \%(77 \%-83 \%)$ of the $\mathrm{VO}_{2 \text { peak }}$. Each group was expected to expend around $400 \mathrm{kcal}$ per aerobic session, thus the difference in time and intensity to assure each group was approximately equal in energy expenditure. Exercise heart rates were adjusted after the 10-week laboratory visit based on the participant's $\mathrm{VO}_{2 \text { peak }}$ GXT. An exercise technician monitored heart rates every 10 minutes via Polar heart rate monitors during the first two weeks, after which the subjects reported the HR to the exercise technician every 15 - 20 minutes. All exercise sessions took place at Norwich University beginning at $0500 \mathrm{~h}$ Monday-Friday. Each woman was expected to complete the prescribed time and an exercise technician took attendance each day. Participants wore SenseWear monitors (BodyMedia, Inc., Pittsburgh, PA) one day each week to assess energy expenditure and ensure they were expending the correct amount of kcals. After the aerobic portion of the exercise program was completed, under the supervision of a trained assistant, all participants engaged in the same resistance tube training program consisting of 2 sets of 12 - 15 repetitions of the following: 2 days each of chest/triceps/shoulders and back/biceps/legs, and one day of a full-body workout. The workout was concluded with abdominal and flexibility exercises.

\subsection{Statistical Analysis}

Statistical analyses were performed using Excel 2010 data package. Descriptive statistics were calculated and values are reported as means \pm SE. Repeated measures paired t-test (2-tailed) compared the pre-exercise values against 10- and 20-week values within the groups to determine whether there was a significant difference in variables of interest from pre-training and throughout the 20-weeks. A 2-way ANOVA with replication was completed on the variables to assess differences between the groups and over time. Pearson product-moment correlations were conducted to assess the relationship between variables of interest. For all tests, a p-value of $<0.05$ was considered significant.

\section{Results}

\subsection{Subject Characteristics}

Table 1 presents the mean \pm SE pre-training, 10- and 20-week values for both the HIGH and LOW groups. There was a significant difference between the GXT speed $(\mathrm{p}<0.01)$, and resting heart rate $(\mathrm{p}<0.001)$. There were no significant differences among the remaining outcome measures between the two groups at baseline. There was no significant difference between the two training groups for the total estimated daily energy expenditure during the training sessions in the field or during the laboratory trials.

\subsection{Body Mass}

Both groups significantly reduced their body mass from pre-training to 10-weeks (HIGH: $\mathrm{p}<0.001$; LOW: $\mathrm{p}<$ 0.05) and 20-weeks (HIGH: p < 0.01; LOW: p < 0.01), indicating that exercise had an effect on overall loss of mass (Table 1). 


\subsection{Cardiorespiratory Fitness}

Both groups had a significant change in their cardiorespiratory fitness as determined by $\mathrm{VO}_{2 \text { peak }}(\mathrm{ml} / \mathrm{min})$ and peak speed during the GXT. At 10 -weeks into the program, $\mathrm{VO}_{2 \text { peak }}$ significantly increased in both groups (HIGH: $\mathrm{p}<0.05$; LOW: $\mathrm{p}<0.01$ ) and at 20-weeks as well ( $<<0.05$ ). Both groups significantly increased their peak speed over the course of the training program ([10-weeks-HIGH: $p<0.01$; LOW: $p<0.001]$ [20weeks-HIGH and LOW: $\mathrm{p}<0.001])$. There was no significant change in peak heart rate during the GXT in either group (Table 1).

\subsection{Resting Blood Pressure and Heart Rate}

The LOW group had a significant decrease in their systolic blood pressure at 20-weeks $(\mathrm{p}<0.01)$. There was no difference in resting heart rate in either group at any point (Table 1).

\subsection{Circumference Measurements}

At 10-weeks, the HIGH group had a significant reduction in the arm $(\mathrm{p}<0.01)$, waist $(\mathrm{p}<0.05)$, hip $(\mathrm{p}<0.01)$, and thigh ( $\mathrm{p}<0.05)$; the LOW group had a significant loss in the waist and thigh $(\mathrm{p}<0.01)$ and hip regions $(\mathrm{p}<$ 0.001). At 20-weeks, the HIGH group had a significant decrease in the arm, waist, and hip ( $<0.001)$ and thigh $(\mathrm{p}<0.01)$ regions; the LOW group had a significant reduction in all areas as well, arm, hip, and thigh ( $\mathrm{p}<$ $0.001)$, and waist $(\mathrm{p}<0.05)$ (Table 1$)$.

\subsection{Hunger Assessment during Laboratory Trials}

There was no significant difference between the groups or within the groups over the 20-weeks, although there was a non-significant trend for subjects in both groups to report less hunger over the course of the 20-week training period as assessed during the laboratory visits (Figure 1).

\begin{tabular}{|c|c|c|c|c|c|c|}
\hline & \multicolumn{3}{|c|}{ HIGH } & \multicolumn{3}{|c|}{ LOW } \\
\hline & Pre-training & 10-week & 20-week & Pre-training & 10-week & 20-week \\
\hline Age (years) & $43.17 \pm 1.18$ & $43.28 \pm 1.15$ & $43.39 \pm 1.20$ & $45.89 \pm 1.40$ & $46.1 \pm 1.38$ & $46.3 \pm 1.35$ \\
\hline Height (m) & $1.68 \pm 0.02$ & $1.68 \pm 0.02$ & $1.68 \pm 0.02$ & $1.66 \pm 0.01$ & $1.66 \pm 0.01$ & $1.66 \pm 0.01$ \\
\hline Body Mass (kg) & $87.53 \pm 3.22$ & $85.70 \pm 3.06^{*}$ & $84.93 \pm 2.89^{\wedge}$ & $88.06 \pm 2.53$ & $86.78 \pm 2.41^{\#}$ & $85.86 \pm 2.40^{\wedge}$ \\
\hline BMI $\left(\mathrm{kg} / \mathrm{m}^{2}\right)$ & $30.88 \pm 1.14$ & $30.33 \pm 1.09^{\wedge}$ & $29.95 \pm 1.04^{*}$ & $31.99 \pm 0.90$ & $31.53 \pm 0.93^{\#}$ & $31.35 \pm 0.96^{\#}$ \\
\hline$\%$ Body fat & $38.97 \pm 1.89$ & $38.12 \pm 1.56$ & $37.56 \pm 1.62$ & $42.19 \pm 1.21$ & $39.08 \pm 1.55^{\wedge}$ & $39.88 \pm 1.23^{\wedge}$ \\
\hline $\mathbf{V O}_{2 \text { peak }}(\mathrm{ml} / \mathrm{min})$ & $2324 \pm 157$ & $2589 \pm 142.5^{\#}$ & $2773 \pm 166.9^{\#}$ & $1986 \pm 153.2$ & $2450 \pm 163.7^{\wedge}$ & $2690 \pm 182.4^{*}$ \\
\hline SBP rest $(\mathrm{mmHg})$ & $119.41 \pm 3.88$ & $123.39 \pm 4.03$ & $122.31 \pm 4.06$ & $120.82 \pm 3.42$ & $116.12 \pm 3.93^{\#}$ & $112.59 \pm 3.30^{*}$ \\
\hline DBP rest (mmHg) & $81.76 \pm 3.18$ & $83.11 \pm 2.55$ & $80.44 \pm 3.00$ & $82.53 \pm 2.48$ & $79.65 \pm 2.41$ & $79.71 \pm 2.15$ \\
\hline HR rest (bpm) & $67.06 \pm 2.31$ & $66.39 \pm 1.79$ & $66.56 \pm 1.60$ & $72.35 \pm 2.50$ & $70.82 \pm 2.18$ & $72.53 \pm 1.74$ \\
\hline HR max (bpm) & $170.13 \pm 2.83$ & $169.93 \pm 2.55$ & $171.0 \pm 2.46$ & $166.25 \pm 3.06$ & $167.53 \pm 2.56$ & $170.59 \pm 2.36$ \\
\hline $\begin{array}{l}\text { Max GXT Speed } \\
(\mathrm{m} / \mathrm{min})\end{array}$ & $150.19 \pm 5.37$ & $159.13 \pm 5.59^{\#}$ & $178.46 \pm 5.97^{\wedge}$ & $129.07 \pm 3.07$ & $139.97 \pm 3.46^{*}$ & $150.67 \pm 3.79^{*}$ \\
\hline $\operatorname{Arm}(\mathrm{cm})$ & $32.56 \pm 0.99$ & $31.45 \pm 0.82^{\#}$ & $30.73 \pm 0.78^{*}$ & $32.56 \pm 0.70$ & $31.78 \pm 0.65$ & $32.73 \pm 0.65^{*}$ \\
\hline Waist (cm) & $96.59 \pm 3.14$ & $94.33 \pm 2.83^{\#}$ & $91.75 \pm 2.77^{\wedge}$ & $101.11 \pm 2.71$ & $97.44 \pm 2.96^{*}$ & $94.61 \pm 2.73^{*}$ \\
\hline Hip (cm) & $111.87 \pm 2.61$ & $108.51 \pm 2.15^{\wedge}$ & $107.74 \pm 2.39^{*}$ & $117.55 \pm 2.15$ & $113.88 \pm 2.39^{*}$ & $112.85 \pm 2.36^{*}$ \\
\hline Thigh (cm) & $58.53 \pm 1.46$ & $56.06 \pm 1.13^{\#}$ & $54.68 \pm 1.34^{*}$ & $61.27 \pm 1.54$ & $58.77 \pm 1.38^{*}$ & $57.19 \pm 1.65^{*}$ \\
\hline Waist/Hip ratio & $0.864 \pm 0.02$ & $0.871 \pm 0.02$ & $0.852 \pm 0.02$ & $0.859 \pm 0.02$ & $0.855 \pm 0.02$ & $0.842 \pm 0.02$ \\
\hline
\end{tabular}

\footnotetext{
${ }^{\#} \mathrm{p}<0.05,{ }^{\wedge} \mathrm{p}<0.01,{ }^{*} \mathrm{p}<0.001$ represent significance from the pre-training values. Values are mean $\pm \mathrm{SE}$.
} 


\subsection{Energy Intake during Laboratory Trials}

There was a non-significant trend in LOW group to consume more over the course of the 20-weeks, as they consumed $24 \%$ more calories after 20 -weeks of training as compared to only a $4 \%$ increase in the HIGH group (Figure 2).

\subsection{Hormones}

Ghrelin-Total ghrelin concentrations had a significant decrease in the HIGH group from pre- to 20-weeks $(\mathrm{p}<0.01)$. There was a significant increase in ghrelin levels in the LOW group from pre- to 20 -weeks $(\mathrm{p}<0.05)$. Over the course of the 20-weeks of training, there emerged a difference between the two groups $\left(\left[\mathrm{df}_{2,102}, \mathrm{~F}=\right.\right.$ 4.88, $\mathrm{p}=0.009$ ] (Figure 3).

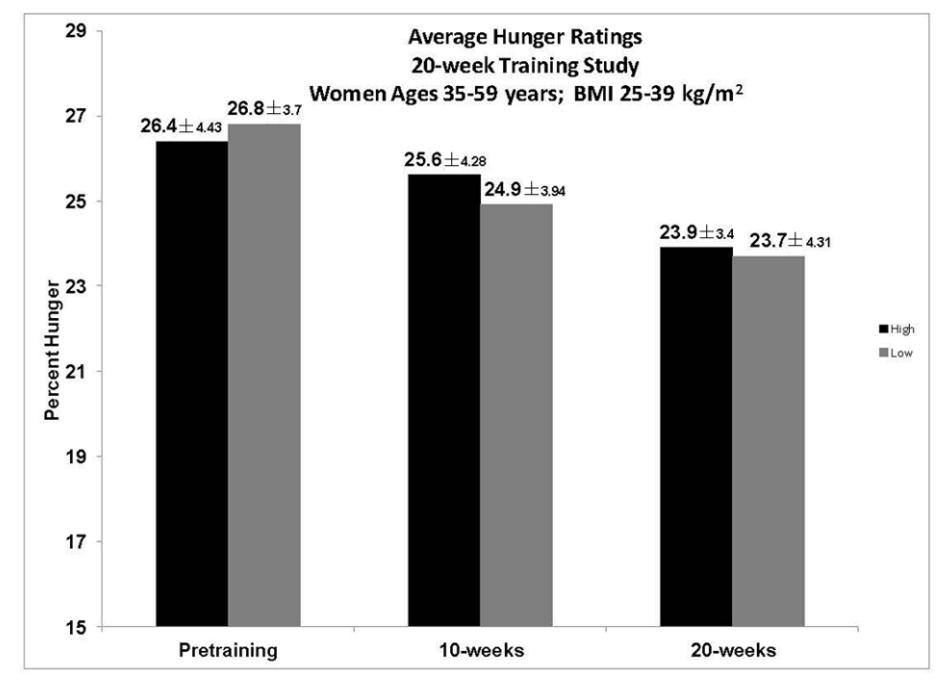

Figure 1. Average percent hunger during the laboratory visit pre-training and at 10 - and 20 -weeks. There was no significant difference between groups, although there was a non-significant trend in both groups for a decrease in hunger over the course of time.

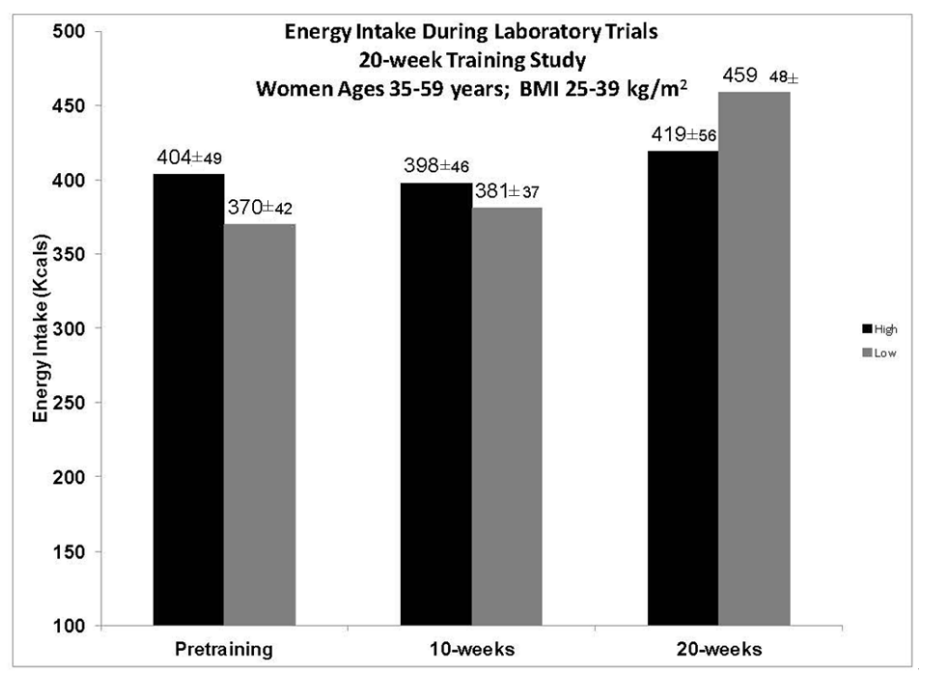

Figure 2. Energy intake during laboratory trials. There was no significant difference in energy intake between the two groups or the trials. There was a non-significant trend for increase food intake by the LOW group at 20-weeks. 
Leptin - Leptin concentrations diminished significantly in both groups over time: HIGH 10-weeks $(\mathrm{p}<0.01)$ and at 20-weeks $(\mathrm{p}<0.05)$; and LOW 10- and 20-weeks $(\mathrm{p}<0.01)$. There was also a difference between the groups over the course of the training period $\left(\left[\mathrm{df}_{1,102}, \mathrm{~F}=5.82, \mathrm{p}=0.02\right]\right.$ (Figure 4).

\subsection{Correlations between Variables}

As expected, the decrease in body mass was correlated with BMI and circumference measurements as well as leptin, when both groups were considered together ( $\mathrm{p}<0.05$; $0.05 ; 0.001)$. There was no correlation with any variables to hunger or ghrelin. When the groups were calculated separately, again, no relationship existed between the variables and hunger or ghrelin. Most of the anthropometric measures were significantly related in

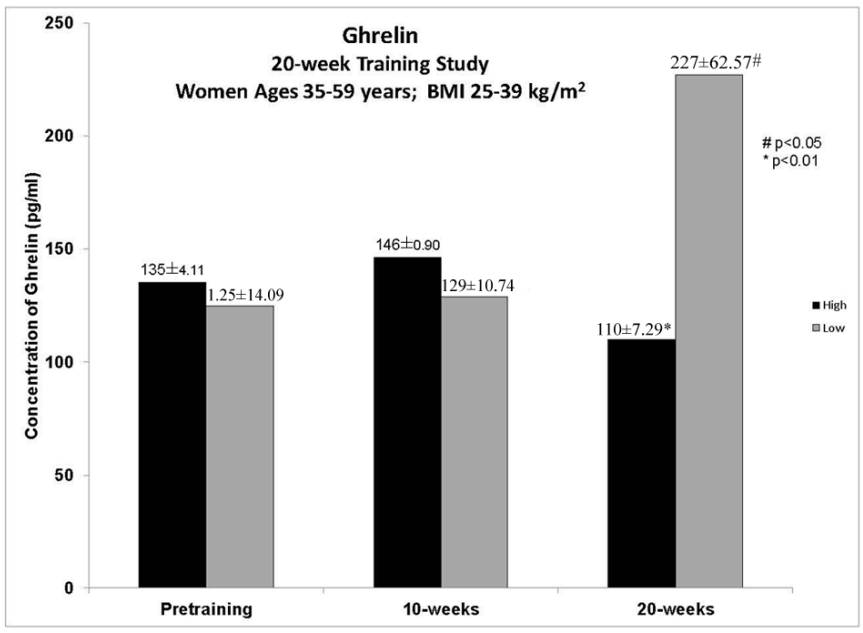

Figure 3. Total ghrelin concentrations during laboratory trials. There was a significant decrease in ghrelin levels in the HIGH group form pre- to 20 -weeks $(\mathrm{p}<0.01)$. There was a significant increase in concentrations in the LOW group form pre- to 20-weeks ( $p<0.05$ ). There was a significant difference in the groups over the 20 -weeks of training $\left(\mathrm{df}_{1,102}, \mathrm{~F}=4.88, \mathrm{p}=0.009\right)$.

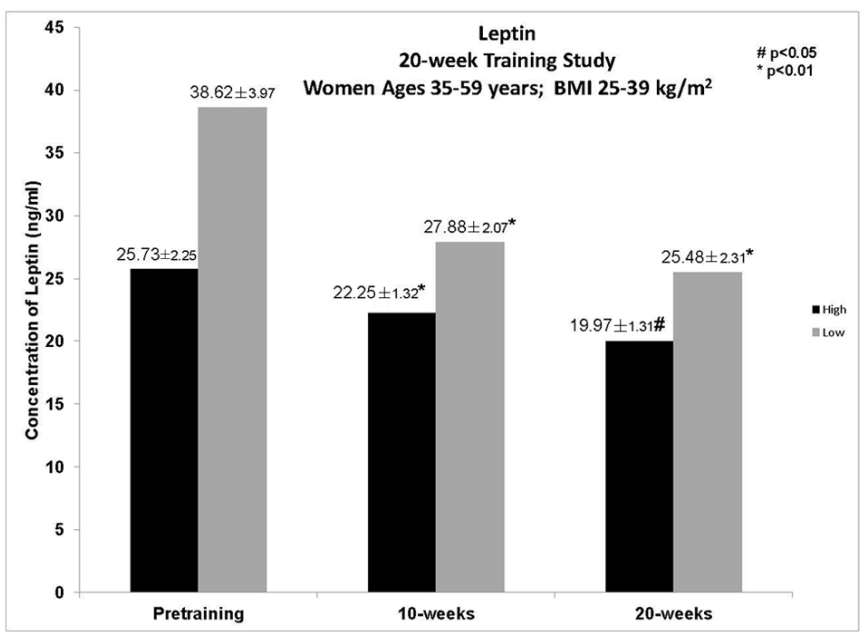

Figure 4. Leptin concentrations during laboratory trials. There was a significant decrease in leptin levels in the HIGH group form preto 10 -week $(\mathrm{p}<0.01)$ and pre- to 20 -weeks $(\mathrm{p}<0.05)$. There was a significant decrease in concentrations in the LOW group form preto 10 -weeks and pre- to 20 -weeks $(\mathrm{p}<0.01)$. There was a significant difference in the groups over the 20 -weeks of training $\left(\mathrm{df}_{1,102}\right.$, $\mathrm{F}=5.82, \mathrm{p}=0.02$ ). 
both groups ( $\mathrm{p}<0.05 ; 0.05 ; 0.001$ ), however there some that did not have any relationship: HIGH: thigh, weight, waist, and leptin; Leptin, weight, waist, arm. LOW: thigh, waist and leptin (see Table 2).

\section{Discussion}

The current study illustrated that by engaging in a well-rounded exercise program utilizing either low- or highintensity aerobic portion, a significant reduction in overall body mass, circumference measurements, and increased cardiorespiratory fitness will occur. There was no significant pre-training difference between the two groups with the exception of maximal speed attained during the $\mathrm{VO}_{2 \text { peak }} \mathrm{GXT}$ and resting heart rate during the laboratory visits.

Of interest was that both groups had a similar decline in overall body mass (Table 1), indicating that it was total caloric expenditure, rather than the intensity of the exercise, that was contributing to overall body mass loss, which agrees with previous studies that have investigated intensity effects [11] [22]. Many participants in exercise programs remain in energy deficit on days where they exercise as compared to sedentary days. Slentz et al. (2004), showed a clear dose-dependent response from sedentary to increasing amounts of caloric expenditure, indicating the more energy expended, the more weight lost. In this current study, the participants exercised 5 days per week with similar energy expenditures through aerobic exercise of differing intensity, along with the same resistance and flexibility training; however there were two days where there was no organized activity, which could be one of the reasons why a greater body mass loss did not occur in both groups. In studies conducted by Woo et al. (1982) [23] when obese women exercised daily, they remained in an energy deficit and had subsequent weight loss as they did not eat more on those days. On exercise days, an energy deficit is likely to

Table 2. Correlation between variables.

\begin{tabular}{|c|c|c|c|c|c|c|c|c|c|c|}
\hline \multicolumn{11}{|c|}{ HIGH } \\
\hline \multirow{10}{*}{ LOW } & & Hunger & Weight & BMI & Waist & Hip & Arm & Thigh & Ghrelin & Leptin \\
\hline & Hunger & & 0.235 & 0.154 & 0.376 & 0.203 & 0.02 & 0.042 & 0.057 & 0.153 \\
\hline & Weight & 0.122 & & $0.87^{*}$ & $0.827^{*}$ & $0.81^{*}$ & $0.63^{\wedge}$ & 0.428 & 0.026 & 0.449 \\
\hline & BMI & 0.07 & $0.82^{*}$ & & $0.652^{\wedge}$ & $0.869^{*}$ & $0.685^{\wedge}$ & $0.639^{\wedge}$ & 0.074 & $0.586^{\#}$ \\
\hline & Waist & 0.144 & $0.761^{*}$ & $0.838^{*}$ & & $0.665^{\wedge}$ & $0.55^{\#}$ & 0.27 & 0.053 & 0.312 \\
\hline & Hip & 0.037 & $0.864^{*}$ & $0.882^{*}$ & $0.816^{*}$ & & $0.519^{\#}$ & $0.568^{\#}$ & 0.049 & $0.73^{\wedge}$ \\
\hline & Arm & 0.087 & $0.681^{\wedge}$ & $0.69^{\wedge}$ & $0.53^{\#}$ & $0.668^{\wedge}$ & & $0.703^{\wedge}$ & 0.069 & 0.248 \\
\hline & Thigh & 0.057 & $0.612^{\#}$ & $0.59^{\#}$ & 0.397 & $0.649^{\wedge}$ & $0.748^{*}$ & & 0.117 & 0.3 \\
\hline & Ghrelin & 0.099 & 0.088 & 0.03 & 0.053 & 0.028 & 0.014 & 0.235 & & 0.19 \\
\hline & Leptin & 0.00001 & $0.513^{\#}$ & $0.612^{\#}$ & $0.62^{\wedge}$ & $0.647^{\wedge}$ & $0.511^{\#}$ & 0.46 & 0.008 & \\
\hline \multicolumn{11}{|c|}{ HIGH and LOW together } \\
\hline & & Hunger & Weight & BMI & Waist & Hip & Arm & Thigh & Ghrelin & \\
\hline \multicolumn{11}{|c|}{ Hunger } \\
\hline & Weight & 0.058 & & & & & & & & \\
\hline & BMI & 0.118 & $0.831^{*}$ & & & & & & & \\
\hline & Waist & 0.26 & $0.777^{*}$ & $0.739^{*}$ & & & & & & \\
\hline & Hip & 0.122 & $0.803^{*}$ & $0.868^{*}$ & $0.748^{*}$ & & & & & \\
\hline & Arm & 0.024 & $0.651^{*}$ & $0.678^{*}$ & $0.528^{\wedge}$ & $0.562^{*}$ & & & & \\
\hline & Thigh & 0.014 & $0.501^{\wedge}$ & $0.614^{*}$ & $0.346^{\#}$ & $0.618^{*}$ & $0.7^{*}$ & & & \\
\hline & Ghrelin & 0.017 & 0.084 & 0.058 & 0.006 & 0.055 & 0.032 & 0.2 & & \\
\hline & Leptin & 0.073 & $0.448^{\wedge}$ & $0.598^{*}$ & $0.481^{\wedge}$ & $0.696^{*}$ & $0.345^{\#}$ & $0.401^{\#}$ & 0.1 & \\
\hline
\end{tabular}

$\# \mathrm{p}<0.05, \wedge \mathrm{p}<0.01,{ }^{*} \mathrm{p}<0.001$ represent significance from the Pre-training values. Values are mean $\pm \mathrm{SE}$. 
occur, although in some individuals, there may be some compensation. Moreover, it is important to remember that even modest changes in body mass can bring about significant health changes [24]. Further investigations are necessary to determine the amount of daily exercise energy expenditure and how many days per week are needed to induce a weight change.

In short-term laboratory studies, HIGH has been shown to decrease hunger and EI [6] [25]. An indirect observation of this study considered whether HIGH could sustain decreased hunger over the course of a day, and over 20-weeks, thereby creating a larger energy deficit as compared to LOW. The hypothesis was that participants in LOW would not experience the same degree of hunger suppression and consume more kcals during the course of the day and over the 20 -weeks, thereby not losing as much weight as HIGH, who would have more hunger suppression on the exercise days. By design, both groups were to expend the same amount of kcals through the exercise program in order to observe whether greater hunger suppression, due to the difference in aerobic exercise intensity, would result in a greater body mass loss. During the laboratory trials, hunger was not significantly different between the groups or over the course of the 20-weeks, in response to a $\mathrm{VO}_{\text {2peak }} \mathrm{GXT}$ (Figure 1), which was not surprising since the response was to peak exercise. EI was measured by an Ad libitum meal presenting 30-minutes post-exercise to observe whether there was a change over the training period or between the groups in response to the $\mathrm{VO}_{2 \text { peak }} \mathrm{GXT}$. There was no observable difference between the groups, but the LOW group had a non-significant trend to consume more by the 20-week trial (Figure 2), which was of interest due to the concomitant change in ghrelin concentrations. Examining the intensity effect on hunger and EI by having the participants complete their regular workout during the laboratory trials, would have provided more specific information needed to interpret why no significant difference in body mass between the two groups was seen over the 20 -week period. As suggested in previous work, there could be EI changes in response to exercise that occurred over time that were not elucidated by short-term studies [9] [26] [27]. Hunger had no correlation to any of the variables in the study indicating that hunger changes were not significantly affected over time and perhaps would not have an overall effect during the course of the 20-weeks.

By 10-weeks there were significant circumference changes in all regions in HIGH, and all but the arm in LOW. By the 20-week point, both groups had changes in all four areas. Of particular importance were the changes in the abdominal region, as a waist circumference of $>88 \mathrm{~cm}$ and waist-to-hip ratio of $>0.85$, in women, are considered risk factors for cardiovascular disease [4] [28], and a better predictor of mortality than BMI [29] [30]. This is of concern for middle-aged women as they approach menopause, as there is the potential for weight gain during that time, specifically an increase in fat depots in the abdominal area [31], thus a greater cardiovascular risk and mortality from associated diseases. Both groups had waist circumferences over the $88 \mathrm{~cm}$ benchmark, as well as waist-to-hip ratios of $>0.85$ before training; however, both had significant changes over the course of the 20-weeks, with an average reduction of 5 - $6 \mathrm{~cm}$ in the waist circumference, bringing waist-to-hip ratios down to 0.85 . If the subjects continued with the program beyond the 20 -weeks, it is conceivable that additional losses in the abdominal region would have occurred.

Increased cardiorespiratory fitness has been linked to a reduction in cardiometabolic risk [32], especially those associated with metabolic syndrome risk factors [33]. The participants in this study had significant changes in their $\mathrm{VO}_{2 \text { peak }}$ in response to a GXT. The HIGH participants had an $18 \%$ and LOW a $28 \%$ increase in their $\mathrm{VO}_{2 \text { peak }}$. Although it appears the LOW group had a larger change in cardiorespiratory fitness, it could also be due to the initial fitness levels of the participants, as HIGH had a slightly higher fitness level at baseline. Other factors to consider are pain or fatigue tolerance, comfortableness of the participants walking/running on the treadmill, and adaptation to wearing metabolic measurement equipment (i.e. mask and headgear with hoses attached). The same could be said for maximal speed during the GXT; both groups had a significant increase in speed attained. Surprisingly, only LOW participants had a significant change in SBP, which could have been due to any number of situations where they could have engaged in physical activity of higher intensity to elicit cardiovascular changes not seen in the other group. At the 20-week trial there were no changes in DBP, as might be expected over the course of an exercise program [34] [35].

The concentrations of total ghrelin changed in opposite directions between the two groups. LOW showed an increased in ghrelin at the 20-week trial, which is similar to what has been reported in other studies where a loss in body mass has occurred [14] [36]. Interestingly, LOW had an $82 \%$ increase in ghrelin levels which was accompanied by a $24 \%$ increase in the test meal during the laboratory trial, yet the subjects reported a $12 \%$ decrease in hunger. This could indicate that subjects were not accurate in their assessment of hunger as there was no correlation between hunger and other variables. HIGH had a significant decrease in ghrelin levels by the 
20-weeks which were accompanied by a 9\% decrease in hunger also noted by others [15] [37]. The diminished ghrelin levels in HIGH could explain why subjects did not consume more kcals at the test meal (4\% increase) as compared to the LOW group (24\% increase). In laboratory trials where subjects underwent sprint and endurance trials, subjects had a greater decrease in ghrelin levels following sprint exercise [38]. In the laboratory, all subjects in this study underwent a $\mathrm{VO}_{2 \text { peak }} \mathrm{GXT}$ rather than the separate workouts, implying that it was the training, rather than the test, that was responsible for the changes seen in ghrelin concentrations. The conundrum remains, LOW had a significant increase in ghrelin, yet HIGH had a decrease at 20-weeks. Ghrelin has been shown to increase rapidly in response to acute energy deficits [39] as well as long term deficits that result in weight loss [13] or no weight loss [40], indicating that ghrelin can be sensitive to both short and long-term energy availability and weight regulation [13]. In the current study, LOW results support this theory; however HIGH does not. This could be due to a plateau in HIGH in terms of body fat loss as compared to LOW, having a full body composition assessment may have elucidated the difference between the groups. Another possible explanation could be the changes in PYY; although not measured in the current study, it was shown previously that PYY directly inhibits ghrelin neurons, indicating that PYY should be considered when examining the changes in ghrelin and its' effects [18].

The secretion of leptin diminished significantly over the course of the 20-weeks for both groups, along with a decrease in subjects' body mass and circumference measurements seen by others following exercise [7] [19]. This decrease in leptin could stimulate an increased drive for EI, thereby attenuating the amount of body mass lost through exercise-induced energy expenditure. Leptin was significantly different depending on the group the subjects were in, as LOW $=34 \%$ and HIGH $=22.4 \%$ decrease in leptin levels. The increased leptin levels at baseline in the LOW group and subsequent larger change in leptin concentrations at 20-weeks could indicate a greater body fat mass. It could be surmised LOW consumed more kcals at the 20-week trial as compared to baseline due to a greater decrease in leptin and an increase in ghrelin. If total body composition could have been measured, again, it may have illuminated whether the changes in body fat could explain, in part, the changes seen in leptin and ghrelin.

Limitations of the study: The inability to measure regional fat and fat-free mass to observe changes that may have occurred as a result of the training programs was a limiting factor as it takes approximately 12-weeks to see appreciable changes in muscle mass, which can contribute to overall health through increased bone mass, metabolism, and insulin sensitivity to name a few [5]. It is of interest to observe specific changes that occurred as a result of the 20-weeks, with varied aerobic intensity and identical resistance and flexibility training. During the laboratory trials the hunger measurements were in response to a $\mathrm{VO}_{2 \text { peak }} \mathrm{GXT}$ rather than the varied intensity aerobic workout. It may have provided more conclusive evidence as to how the participants felt, in terms of hunger, to have had them do their regular exercise routine rather than a GXT; however a GXT was necessary in order to make adjustments in the participants exercise prescription. Not having the subjects complete a restrained eating questionnaire to determine whether they would have changed their eating patterns during the laboratory trials would have also provided important information. Lastly, is would have been interesting to observe one-year post-training if the participants continued with their exercise routine and maintained the body mass loss that occurred while training.

\section{Practical Applications}

The major findings of this study were that both LOW and HIGH can have positive effects on body mass loss, reduced circumferences, increased $\mathrm{VO}_{2 \text { peak, }}$ and an increase in the speed during a GXT. Overall body mass loss in response to aerobic exercise is not dependent on intensity; it will occur regardless, especially when combined with a resistance and flexibility program, provided the energy expenditure is the same. Health benefits are likely to occur with either intensity of exercise, however HIGH requires less time during the day. Consideration must be given to whether it is the suppression of hunger to prevent excess caloric intake or the energy expenditure of exercise that has the greatest contribution to the energy deficit created on a daily basis, thereby influencing weight loss or prevention of weight gain. The effects of the changing hormonal milieu on subsequent EI and hunger levels, during exercise days, should be elucidated. Further investigation is needed into the actual body mass changes in terms of fat and fat-free mass related to well-rounded exercise programs that vary the intensity of the aerobic portion and incorporate resistance and flexibility training. 


\section{Acknowledgements}

The authors wish to thank all the participants of this study. The project described was supported by the Vermont Genetics Network through Grant Number P20 RR16462 from the INBRE Program of the National Center for Research Resources (NCRR), a component of the National Institutes of Health (NIH). Its contents are solely the responsibility of the authors and do not necessarily represent the official views of NCRR, NIH, or ACSM.

\section{Conflict of Interest}

The authors have no conflict of interests to declare.

\section{Funding}

The project described was supported by the Vermont Genetics Network through Grant Number P20 RR16462 from the INBRE Program of the National Center for Research Resources (NCRR), a component of the National Institutes of Health (NIH). Its contents are solely the responsibility of the authors and do not necessarily represent the official views of NCRR, NIH, or ACSM. The authors have no conflict of interests to declare.

\section{References}

[1] Flegal, K.M., Carroll, M.D., Ogden, C.L. and Curtin, L.R. (2010) Prevalence and Trends in Obesity among US Adults, 1999-2008. Journal of the American Medical Association, 303, 235-241. http://dx.doi.org/10.1001/jama.2009.2014

[2] National Center for Health Statistics (2010) NHANES Reference Manuals and Reports. Hyattsville, MD: U.S. Department of Health and Human Services, Public Health Service, CDC. CDC Vital Signs: Adult Obesity, 1-4. http://www.cdc.gov/obesity/resources/factsheets.html

[3] World Health Organization Statistics. World Health Organization, Washington DC. http://www.who.int/mediacentre/factsheets/fs311

[4] American Heart Association Web Site [Internet] (2012) Understanding the American Obesity Epidemic. American Heart Association, Dallas. [Cited 2012 Nov. 1]. http://www.americanheart.org

[5] Garber, C.E., Blissmer, B., Deschenes, M.R., Franklin, B.A., Lamonte, M.J., Lee, I.M., et al. (2011) Quanitity and Quality of Exercise for Developing and Maintaining Cardiorespiratory, Musculoskeletal, and Neuromotor Fitness in Apparently Healthy Adults: Guidance for Prescribing Exercise. Medicine and Science in Sports and Exercise, 43, 1334-1359. http://dx.doi.org/10.1249/MSS.0b013e318213fefb

[6] Thompson, D.A., Wolfe, L.A. and Eikelboom, R. (1988) Acute Effects of Exercise Intensity on Appetite in Young Men. Medicine and Science in Sports and Exercise, 20, 222-227. http://dx.doi.org/10.1249/00005768-198806000-00002

[7] Trapp, E.G., Chisholm, D.J., Freund, J. and Boutcher, S.H. (2008) The Effects of High-Intensity Intermittent Exercise Training on Fat Loss and Fasting Insulin Levels of Young Women. International Journal of Obesity, 32, 684-691. http://dx.doi.org/10.1038/sj.ijo.0803781

[8] Woo, R., Garrow, J.S. and Pi-Sunyer, F.X. (1982) Voluntary Food Intake during Prolonged Exercise in Obese Women. The American Journal of Clinical Nutrition, 36, 478-484.

[9] Whybrow, S., Hughes, D.A., Ritz, P., Johnstone, A.M., Horgan, G.W., King, N., et al. (2008) The Effect of an Incremental Increase in Exercise on Appetite, Eating Behavior, and Energy Balance in Lean Young Men and Women Feeding Ad libitum. British Journal of Nutrition, 100, 1109-1115. http://dx.doi.org/10.1017/S0007114508968240

[10] Foster-Shubert, K.E., Alfano, C.M., Duggan, C.R., Xiao, L., Campbell, K.L., Kong, A., et al. (2012) Effect of Diet and Exercise, Alone or Combined, on Weight and Body Composition in Overweight-to-Obese Postmenopausal Women. Obesity, 20, 1628-1638. http://dx.doi.org/10.1038/oby.2011.76

[11] Slentz, C.A., Duscha, B.D., Johnson, J.L., Ketchum, K., Aiken, L.B., Samsa, G.P., et al. (2004) Effects of the Amount of Exercise on Body Weight, Body Composition, and Measures of Central Obesity: STRIDDE-A Randomized Controlled Study. Archives of Internal Medicine, 164, 31-39. http://dx.doi.org/10.1001/archinte.164.1.31

[12] Wang, X., Lyles, M.F., You, T., Berry, M.J., Rejeski, W.J. and Nicklas, B.J. (2008) Weight Regain Is Related to Decreases in Physical Activity during Weight Loss. Medicine and Science in Sport and Exercise, 40, 1781-1788.

[13] Scheid, J.L., De Souza, M.J., Leidy, H.J. and Williams, N.I. (2011) Ghrelin but Not Peptide YY Is Related to Change in Body Weight and Energy Availability. Medicine and Science in Sport and Exercise, 43, 2063-2071. http://dx.doi.org/10.1249/MSS.0b013e31821e52ab 
[14] Cummings, D.E., Purnell, J.O., Frayo, R.S., Schmidova, K., Wisse, B.E. and Weigle, D.S. (2001) A Preprandial Rise in Plasma Ghrelin Levels Suggests a Role in Meal Initiation in Humans. Diabetes, 50, 1714-1719. http://dx.doi.org/10.2337/diabetes.50.8.1714

[15] Broom, D.R., Batterham, R.L., King, J.A. and Stensel, D.J. (2009) Influence of Resistance and Aerobic Exercise on Hunger, Circulating Levels of Acylated Ghrelin, and Peptide YY in Healthy Males. American Journal of Physiology, 296, R29-R35. http://dx.doi.org/10.1152/ajpregu.90706.2008

[16] King, J.A., Wasse, L.K., Ewens, J., Crystallis, K., Emmanuel, J., Batterham, R.L., et al. (2011) Differential Acylated Ghrelin, Peptide $\mathrm{YY}_{3-36}$, Appetite, and Food Intake Responses to Equivalent Energy Deficits Created by Exercise and Food Restriction. Journal of Clinical Endocrinology and Metabolism, 96, 1114-1121. http://dx.doi.org/10.1210/jc.2010-2735

[17] Considine, R.V., Considine, E.L., Williams, C.J., Hyde, T.M. and Caro, J.F. (1996) The Hypothalamic Leptin Receptor in Humans: Identification of Incidental Sequence Polymorphisms and Absence of the db/db Mouse and fa/fa Mutations. Diabetes, 45, 992-994. http://dx.doi.org/10.2337/diab.45.7.992

[18] Riediger, T., Bothe, C., Becskei, C. and Lutz, T.A. (2004) Peptide YY Directly Inhibits Ghrelin-Activated Neurons of the Arcuate Nucleus and Reverses Fasting-Induced c-Fos Expression. Neuroendocrinology, 79, 317-326. http://dx.doi.org/10.1159/000079842

[19] Potteiger, J.A., Jacobsen, D.J., Donnelly, J.E. and Hill, J.O. (2003) Glucose and Insulin Responses Following 16 Months of Exercise Training in Overweight Adults: The Midwest Exercise Trial. Metabolism, Clinical and Experimental, 52, 1175-1181. http://dx.doi.org/10.1016/S0026-0495(03)00146-X

[20] Rosenbaum, M., Goldsmith, R., Bloomfield, D., Magnano, A., Weimer, L., Heymsfield, S., et al. (2005) Low-Dose Leptin Reverses Skeletal Muscle, Autonomic, and Neuroendocrine Adaptations to Maintenance of Reduced Weight. Journal of Clinical Investigation, 115, 3579-3586. http://dx.doi.org/10.1172/JCI25977

[21] Hill, A.J. and Blundell, J.E. (1982) Nutrients and Behavior: Research Strategies for the Investigation of Taste Characteristics, Food Preferences, Hunger Sensations and Eating Patterns in Man. Journal of Psychiatric Research, 17, 203212. http://dx.doi.org/10.1016/0022-3956(82)90023-1

[22] Grediagin, A., Cody, M., Rupp, J., Benardot, D. and Shern, R. (1995) Exercise Intensity Does Not Effect Body Composition Change in Untrained, Moderately Overfat Women. Journal of the American Dietetic Association, 95, 661-665. http://dx.doi.org/10.1016/S0002-8223(95)00181-6

[23] Woo, R., Garrow, J.S. and Pi-Sunyar, F.X. (1982) Effect of Exercise on Spontaneous Calorie Intake in Obesity. American Journal of Clinical Nutrition, 36, 470-477.

[24] Pi-Sunyar, F.X. (1996) A Review of Long-Term Studies Evaluating the Efficacy of Weight Loss in Ameliorating Disorders Associated with Obesity. Clinical Therapy, 18, 1006-1035. http://dx.doi.org/10.1016/S0149-2918(96)80057-9

[25] Ueda, S.Y., Yoshikawa, T., Katsura, Y., Usui, T., Nakao, H. and Fujimoto, S. (2009) Changes in Gut Hormone Levels and Negative Energy Balance during Aerobic Exercise in Obese Young Males. Journal of Endocrinology, 201, 151159. http://dx.doi.org/10.1677/JOE-08-0500

[26] Finlayson, G., Bryant, E., Blundell, J.E. and King, N.A. (2009) Acute Compensatory Eating Following Exercise Is Associated with Implicit Hedonic Wanting for Food. Physiology and Behavior, 97, 62-67. http://dx.doi.org/10.1016/j.physbeh.2009.02.002

[27] Stubbs, R.J., Sepp, A., Hughes, D.A., Johnstone, A.M., King, N., Horgan, G., et al. (2002) The Effect of Graded Levels of Exercise on Energy Intake and Balance in Free-Living Women. International Journal of Obesity, 26, 866-869.

[28] Yusuf, S., Hawken, S., Ounpuu, S., Dans, T., Avezum, A., Lanas, F., et al. (2004) Effect of Potentially Modifiable Risk Factors Associated with Myocardial Infarction in 52 Countries (the INTERHEART Study): Case-Control Study. The Lancet, 364, 937-952. http://dx.doi.org/10.1016/S0140-6736(04)17018-9

[29] Petursson, H., Sigurdsson, J.A., Bengtsson, C., Nilsen, T.I. and Getz, L. (2011) Body Configuration as a Predictor of Mortality: Comparison of Five Anthropometric Measures in a 12-Year Follow-Up of the Norwegian HUNT2 Study. PLoS ONE, 6, e26621. http://dx.doi.org/10.1371/journal.pone.0026621

[30] Price, G.M., Uauy, R., Breeze, E., Bulpitt, C.J. and Fletcher, A.E. (2006) Weight, Shape, and Mortality Risk in Older Persons: Elevated Waist-Hip Ratio, Not High Body Mass Index, Is Associated with a Greater Risk of Death. American Journal of Clinical Nutrition, 84, 449-460.

[31] Jurimae, J. and Jurimae, T. (2007) Plasma Adiponectin Concentration in Healthy Pre- and Post-Menopausal Women: Relationship with Body Composition, Bone Mineral and Metabolic Variables. American Journal of Physiology, 293, E642-E647.

[32] Grundy, S.M., Barlow, C.E., Farrell, S.W., Vega, G.L. and Haskell, W.L. (2012) Cardiorespiratory Fitness and Metabolic Risk. American Journal of Cardiology, 109, 988-993. http://dx.doi.org/10.1016/j.amjcard.2011.11.031

[33] King, N.A., Lluch, A., Stubbs, R.J. and Blundell, J.E. (1997) High Dose Exercise Does Not Increase Hunger or Energy 
in Free Living Males. European Journal of Clinical Nutrition, 51, 478-483. http://dx.doi.org/10.1038/sj.ejcn.1600432

[34] Amin-Shokravi, F., Rajabi, R. and Ziaee, N. (2011) Exercise Effects on Risk of Cardiovascular Disease among Iranian Women. Asian Journal of Sports Medicine, 2, 37-43.

[35] US Department of Health and Human Services (2008) Physical Activity Guidelines Advisory Committee Report, 2008. ODPHP Publication No. U0049, Washington DC, 683 p.

[36] Cummings, D.E. and Overduin, J. (2007) Gastrointestinal Regulation of Food Intake. Journal of Clinical Investigation, 117, 13-23. http://dx.doi.org/10.1172/JCI30227

[37] Broom, D.R., Stensel, D.J., Bishop, N.C., Burns, S.F. and Miyashita, M. (2007) Exercise-Induced Suppression of Acylated Ghrelin in Humans. Journal of Applied Physiology, 102, 2165-2171. http://dx.doi.org/10.1152/japplphysiol.00759.2006

[38] Deighton, K., Barry, R., Connon, C.E. and Stensel, D.J. (2013) Appetite, Gut Hormone and Energy Intake Responses to Low Volume Sprint Interval and Traditional Endurance Exercise. European Journal of Applied Physiology, 113, 1147-1156. http://dx.doi.org/10.1007/s00421-012-2535-1

[39] Borer, K.T., Wuorinen, E., Ku, K. and Burant, C. (2009) Appetite Responds to Changes in Meal Content, Whereas Ghrelin, Leptin, and Insulin Track Changes in Energy Availability. Journal of Clinical Endocrinology and Metabolism, 94, 2290-2298. http://dx.doi.org/10.1210/jc.2008-2495

[40] Ravussin, E., Tschop, M., Morales, S., Bouchard, C. and Heiman, M.L. (2001) Plasma Ghrelin Concentration and Energy Balance: Overfeeding and Negative Energy Balance Studies in Twins. Journal of Clinical Endocrinology and Metabolism, 86, 4547-4551. http://dx.doi.org/10.1210/jcem.86.9.8003 
Scientific Research Publishing (SCIRP) is one of the largest Open Access journal publishers. It is currently publishing more than 200 open access, online, peer-reviewed journals covering a wide range of academic disciplines. SCIRP serves the worldwide academic communities and contributes to the progress and application of science with its publication.

Other selected journals from SCIRP are listed as below. Submit your manuscript to us via either submit@scirp.org or Online Submission Portal.
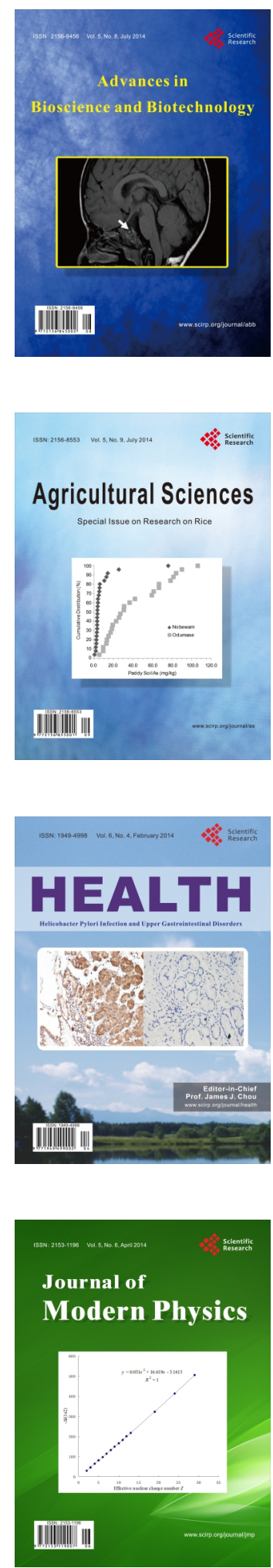
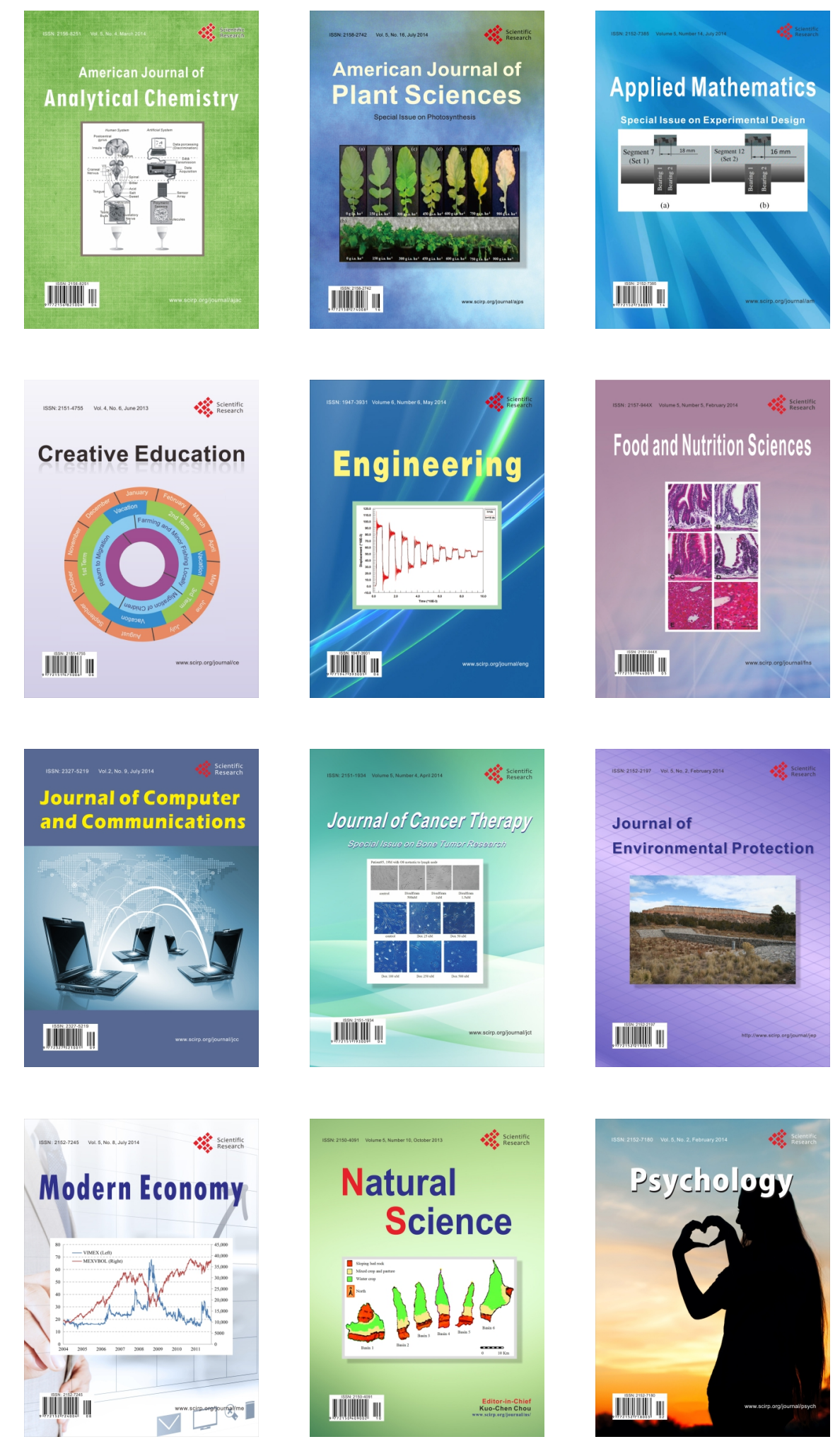